\title{
A double gallbladder with a common bile duct stone treated by laparoscopy accompanied by choledochoscopy via the cystic duct: A case report
}

\author{
WEI YU, HUISHENG YUAN, SHI CHENG, YING XING and WENMAO YAN \\ Department of General Surgery, Beijing Tiantan Hospital, Capital Medical University, Beijing 100050, P.R. China
}

Received August 23, 2015; Accepted August 23, 2016

DOI: $10.3892 / \mathrm{etm} .2016 .3834$

\begin{abstract}
A double gallbladder is a rare congenital malformation. The present study describes a case of double gallbladder with secondary common bile duct stones. By way of laparoscopic choledochoscopy, the exploration and removal of a common bile duct stone was performed through the cystic duct. The process involved a primary suture of the cystic duct and was performed without using a T-tube, and completed a surgical removal of the gallbladder. The present case was successfully treated by laparoscopic surgery. From a review of previous studies published in the English language, this study, to the best of our knowledge, is the first report of such a case. Therefore, laparoscopic dissection is safe for the removal of a double gallbladder and for exploration of the common duct by choledochoscopy.
\end{abstract}

\section{Introduction}

Double gallbladder is a biliary anomaly with an incidence of 1 case per 3,800-4,000 patients (1). It is typically not diagnosed preoperatively, but is incidentally identified intraoperatively (2). However, this condition may be missed during the surgery and diagnosed during a postoperative endoscopic retrograde cholangio-pancreatography examination performed for persistent biliary symptoms $(3,4)$. In order to avoid intraoperative injury, open-surgery is a common treatment strategy. Gorecki et al (5) reported a case of double gallbladder originating from the left hepatic duct during a laparoscopic surgery, which was then converted to an open procedure due to the absence of the accessory cystic duct. However, this surgical procedure results in several risks. Therefore, the present study suggests the importance of double gallbladder diagnosis to avoid complications and careful surgery to complete the laparoscopic surgery.

Correspondence to: Dr Wei Yu, Department of General Surgery, Beijing Tiantan Hospital, Capital Medical University, 6 Tian Tan Xi Li, Beijing 100050, P.R. China

E-mail: yuweimade@sina.com

Key words: double gallbladder, common bile duct stone, laparoscopy, choledochoscopy
The current study describes a case of a manifestly complex inflammatory double gallbladder in a 66-year-old woman with secondary common bile duct (CBD) stones. A laparoscopic choledochoscopy were performed to explore and remove a common bile duct stone through the cystic duct without using a T-tube, and the gallbladder was surgically removed. To the best of our knowledge, this is the first of such cases to be reported in the English language. It is safe and feasible to identify the anatomical association, move the gallbladder and explore the entire biliary duct through the use of laparoscopic choledochoscopy without postoperative complications.

\section{Case report}

The patient was a 66-year-old woman with whose primary complaint was intermittent epigastric and right upper quadrant pain, which she had experienced for $\sim 3$ years. The episodes did not involve fever or jaundice and relieved by anti-inflammatory treatment with ceftazilime (Hainan HaiLing Chemical Pharmaceutical Co., Ltd., Hainan, China; 2 g twice a day, by intravenous drip). The episodes were frequent, with the pain experienced by the patient upon admission to hospital presenting in the upper abdomen and right upper quadrant for $>1$ month without fever or jaundice. The patient presented with physical weakness and a lack of appetite, and brown feces and pale yellow urine were observed. Upon admission to the Beijing Tiantan Hospital (Beijing, China) in April 2014, the patient had a body temperature of $36.5^{\circ} \mathrm{C}$ and a heart rate of $70 \mathrm{bpm}$ without systemic lymph node enlargement or jaundice of the skin or sclera. There was no evidence of anemia. Her abdomen was flat, and the right upper quadrant showed mild tenderness with no rebound tenderness or muscle tension. Murphy's sign and liver percussion pain assessments were negative. Laboratory tests revealed a normal white blood cell (WBC) count. The amylase, urea, electrolyte and liver function assessments were normal; the total bilirubin level was $12.5 \mu \mathrm{mol} / 1$ (normal range, 5.1-19.0 $\mu \mathrm{mol} / \mathrm{l}$ ), and the direct bilirubin level was $3.2 \mu \mathrm{mol} / 1$, indicating that neither level was elevated. An abdominal B-scan ultrasound revealed a double cavity in the gallbladder region with a thickened wall with a rough surface. A $1.7 \mathrm{~cm}$ hyperechoic mass was observed in one capsule and had an acoustic shadow behind it, which was removable. The extrahepatic bile duct was widened, and the diameter at the widest point was $\sim 1.2 \mathrm{~cm}$. In addition, a stone 

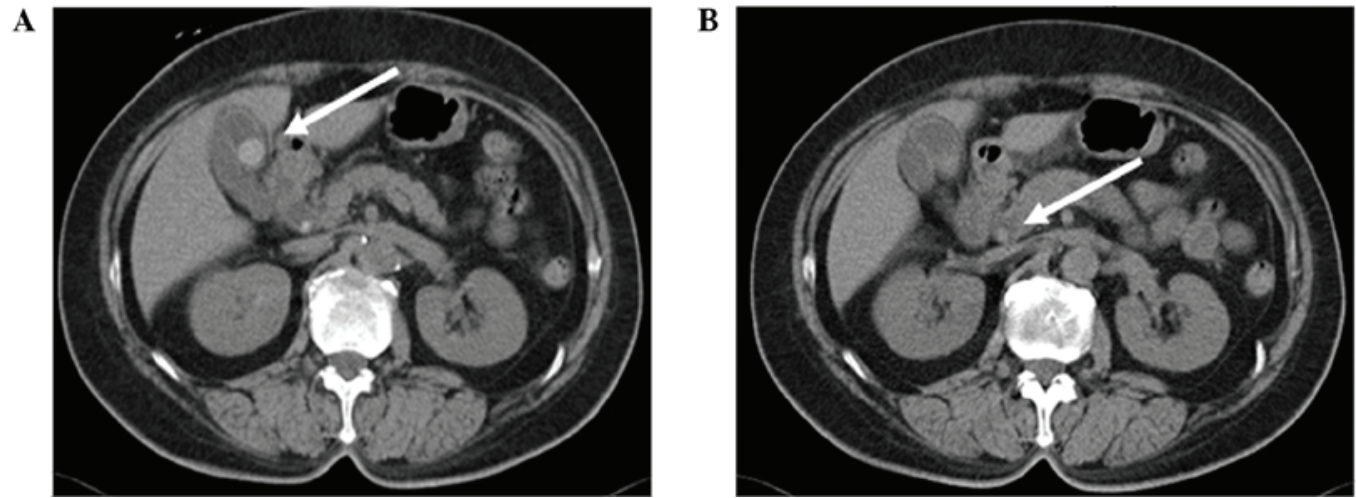

Figure 1. Abdominal computed tomography scan results. (A) A folding gallbladder with a thickened wall and high internal density, with a diameter of $1.2 \mathrm{~cm}$, as indicated by the white arrow. (B) A choledochectasia diameter of $1.4 \mathrm{~cm}$, with high density in the common bile duct and a common bile duct stone with a diameter of $0.4 \mathrm{~cm}$, as indicated by the white arrow.
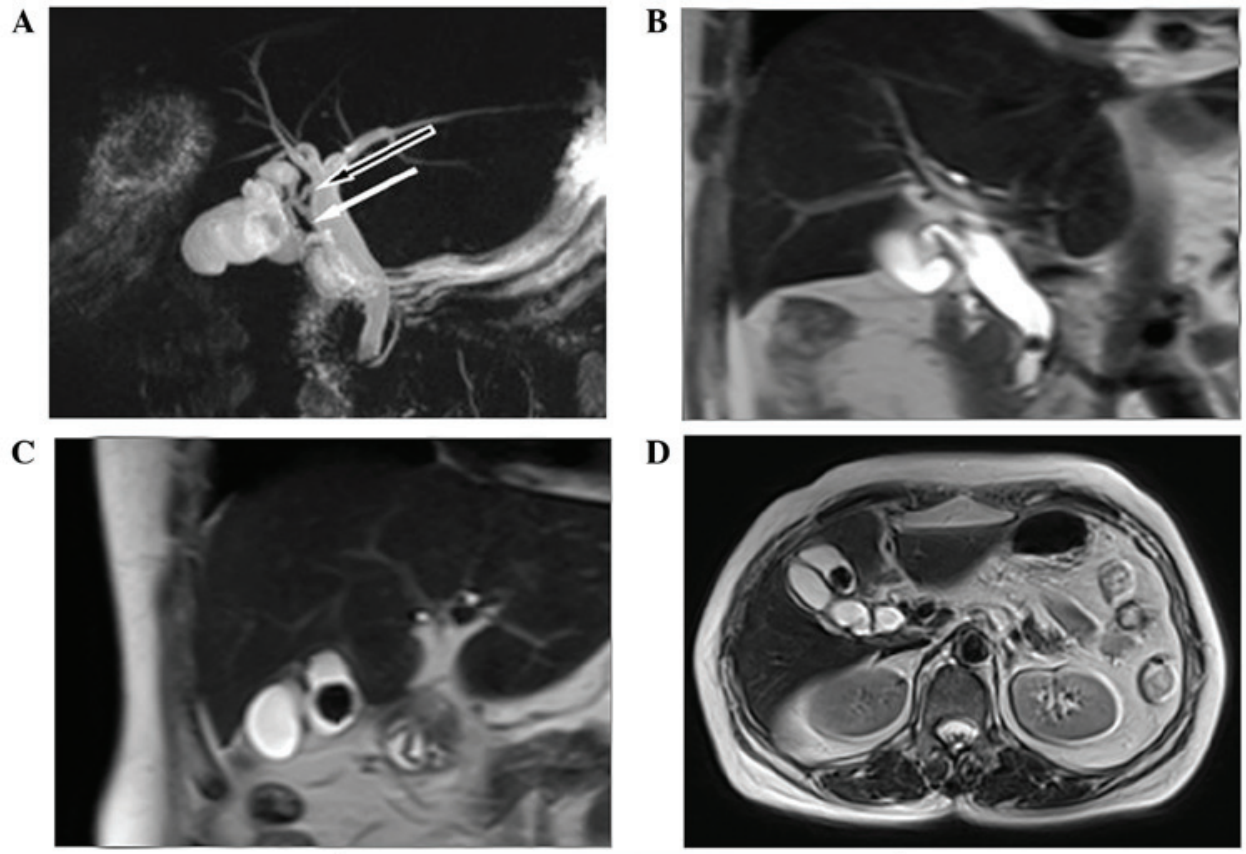

$\mathbf{E}$

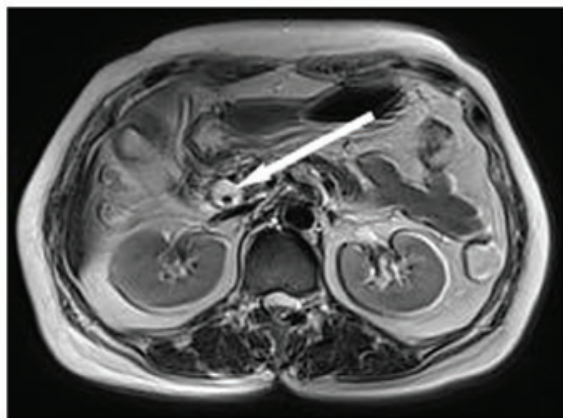

Figure 2. Magnetic resonance cholangiopancreatography results. (A) The reconstruction image shows a double gallbladder with two separated cystic ducts The white arrow indicates the first gallbladder and its duct, and the black arrow indicates the second gallbladder and its duct. (B) The common bile duct stone. (C) Gallstones and (D) crown section; the double gallbladder with gallstones. (E) Crown section; the common bile duct stone, indicated by the white arrow.

was present in the CBD. An abdominal computed tomography scan revealed that the double gallbladder walls were thickened, and a stone with clear boundaries was observed. The choledochectasia had a diameter of $1.4 \mathrm{~cm}$, and a stone with a diameter of $0.4 \mathrm{~cm}$ was detected in the CBD (Fig. 1). The magnetic resonance cholangiopancreatography (MRCP) findings were as follows: A dual-chamber gallbladder; choledochectasia; gallstones with cholecystitis; and common bile duct stones (Fig. 2). A laparoscopic cholecystectomy (LC) was performed in April 2014. Fibrosis from chronic inflammation caused surgical difficulties. A retrograde resection was performed. Dissection of Calot's triangle was 
A

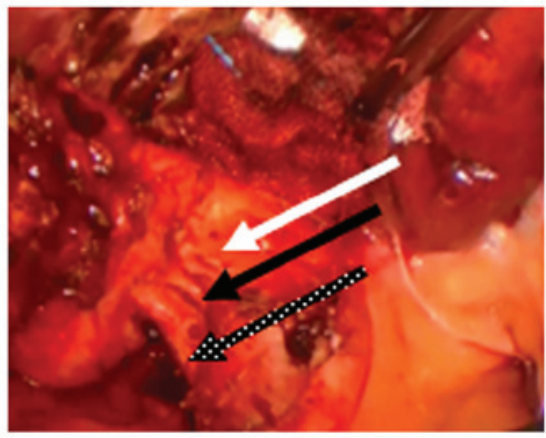

C

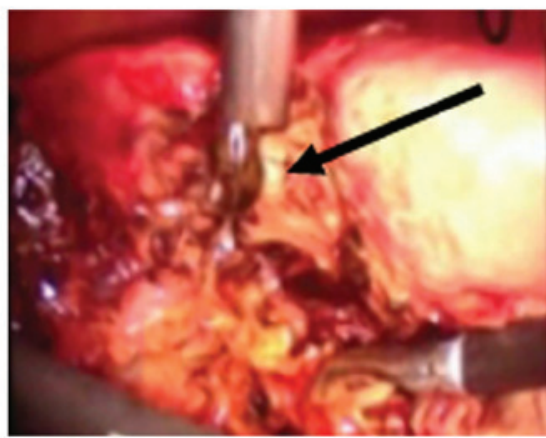

E

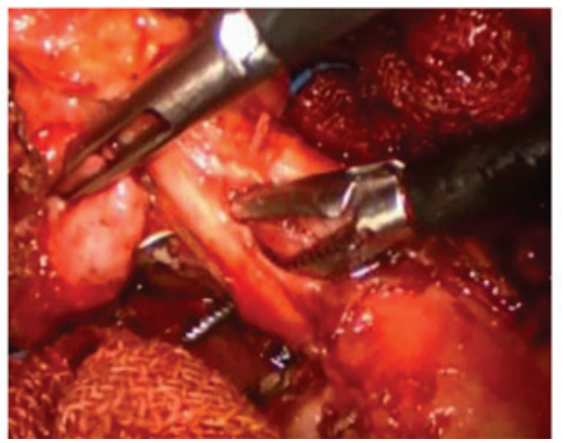

B

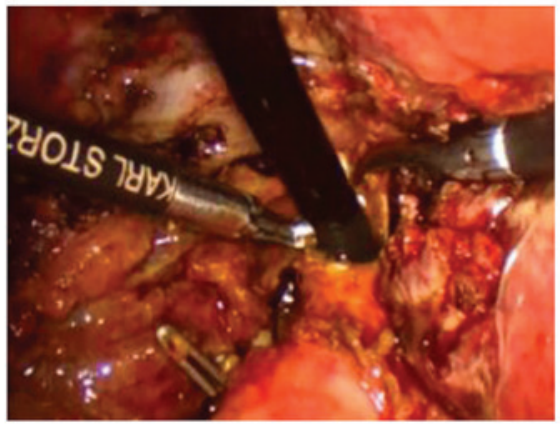

D

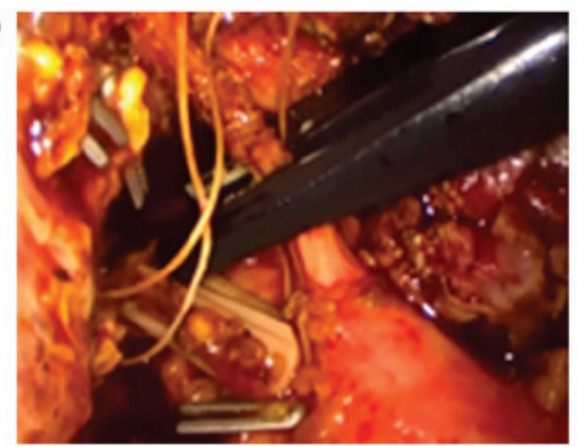

F

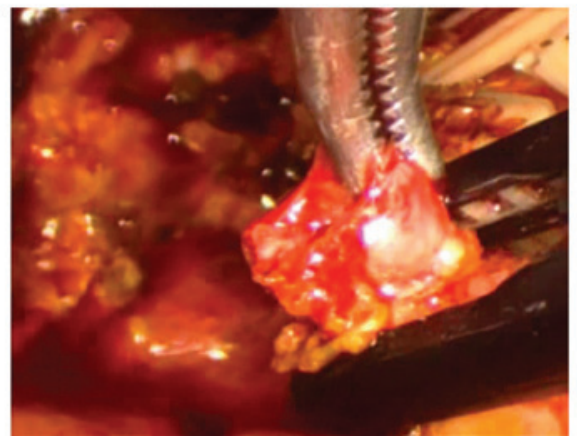

Figure 3. Intraoperative images. (A) A blunt dissection was performed, and the two cystic ducts and one cystic artery were clearly distinguished; however, the structure of the double gallbladder was destroyed. The white arrow indicates the second gallbladder duct, the black arrow indicates the cystic artery and the dotted arrow shows the first gallbladder duct. (B) A micro-incision was made through the anterior wall of the second cystic duct connected with the common bile duct, followed by insertion of the choledochoscope and removal of the stone. (C) The common bile duct stone was removed through choledochoscopic visualization of the cystic duct (indicated by the black arrow). (D) After suturing of the cystic duct, Tyco absorbable clips were set on the second cystic duct, and the damaged gallbladder was completely removed. (E) Tyco absorbable clips were set on the cystic artery. (F) Tyco absorbable clips were set on the first cystic duct.

carefully performed, and two cystic ducts and one cystic artery were readily distinguished. Two cystic ducts were separately connected to the CBD (Fig. 3). A micro-incision was performed through the anterior wall of the second cystic duct and the point of connection to the CBD, and the choledochoscope was inserted and the stone was removed (Fig. 3). The second cystic duct was sutured without the use of a T-tube, and Tyco (Medtronic Inc., Minneapolis, MN, USA) absorbable clips were fixed upon it. The cystic artery and the first cystic duct were set on Tyco absorbable clips separately (Fig. 3). Exploration by choledochoscopy during LC surgery confirmed that the lumen structure was consistent with the results of MRCP. No residual stones were identified and the cystic structure remained unchanged (Fig. 4).

A number of postoperative conditions were noted. There was $50 \mathrm{ml}$ peritoneal drainage from the gallbladder fossa after $16 \mathrm{~h}$ on the first day, and the drainage fluid was pale and contained blood. No bile was observed. The drainage fluid during the subsequent $24 \mathrm{~h}$ amounted to $20 \mathrm{ml}$. The patient did not experience any pain, and her body temperature remained normal. The laboratory test results $16 \mathrm{~h}$ post-surgery showed that the WBC count was $18.61 \times 10^{9} / 1$, which decreased to normal levels without the administration of anti-inflammatory therapies. The alanine transaminase (normal range, 0.0-41.0 IU/1) and aspartate aminotransferase (normal range, 0.0-42.0 IU/l) levels were 99.5 IU/1 and 127 IU/1, respectively. Glutathione (Shandong Green Leaf Pharmaceutical Co., Ltd., Yantai, China) was administered once postoperatively (1.2 g; intravenous drip) to preserve the function of the liver, which recovered rapidly. The total bilirubin and direct bilirubin levels were $16.5 \mu \mathrm{mol} / 1$ and $5.3 \mu \mathrm{mol} / 1$, respectively. Two days post-surgery, the patient began a liquid diet and was discharged the following day.

The microscopic image of the double gallbladder showed chronic cholecystitis. Previous studies concerning double gallbladder cases associated with conditions other than 
Table I. Cases of laparoscopic surgery of double gallbladder associated with circumstances other than cholecystitis and gallstones.

\begin{tabular}{|c|c|c|c|c|c|c|}
\hline $\begin{array}{l}\text { First } \\
\text { author }\end{array}$ & Year & $\begin{array}{l}\text { Associated } \\
\text { circumstance }\end{array}$ & $\begin{array}{l}\text { Preoperative } \\
\text { diagnosis }\end{array}$ & $\begin{array}{l}\text { Second } \\
\text { surgery } \\
\text { required }\end{array}$ & $\begin{array}{l}\text { Intraoperative } \\
\text { complications }\end{array}$ & Ref. \\
\hline Gorecki & 1998 & Originated from the left hepatic duct & $\mathrm{Y}$ & $\mathrm{N}$ & Conversion to $\mathrm{OC}$ & $(5)$ \\
\hline Weibel & 2001 & Originated from the right hepatic duct & $\mathrm{Y}$ & $\mathrm{Y}$ & Conversion to $\mathrm{OC}$ & (6) \\
\hline Schroeder & 2003 & Triple gallbladder & $\mathrm{Y}$ & $\mathrm{N}$ & $\mathrm{N}$ & (7) \\
\hline Ohtani & 2003 & Cholelithiasis adenomyomatosis & $\mathrm{Y}$ & $\mathrm{N}$ & $\mathrm{N}$ & (8) \\
\hline Papaziogas & 2005 & $\begin{array}{l}\text { Two separate cystic ducts connected } \\
\text { through an ostium }\end{array}$ & $\mathrm{N}$ & $\mathrm{N}$ & Conversion to $\mathrm{OC}$ & (9) \\
\hline Sasaki & 2005 & Double gallbladder (duodenal type) & $\mathrm{Y}$ & $\mathrm{N}$ & $\mathrm{N}$ & $(10)$ \\
\hline Vijayaraghavan & 2006 & $\begin{array}{l}\text { Pyocoele acute cholecystitis and } \\
\text { cystadenoma }\end{array}$ & $\mathrm{N}$ & $\mathrm{N}$ & $\mathrm{N}$ & $(11)$ \\
\hline Singh & 2006 & Accompanied by jaundice & $\mathrm{Y}$ & $\mathrm{Y}$ & $\mathrm{N}$ & $(12)$ \\
\hline Lefemire & 2009 & Neuroma of a double gallbladder & $\mathrm{Y}$ & $\mathrm{Y}$ & $\mathrm{N}$ & $(13)$ \\
\hline Walbolt & 2011 & Accompanied by gallstone pancreatitis & $\mathrm{Y}$ & $\mathrm{N}$ & $\mathrm{N}$ & $(14)$ \\
\hline Ghosh & 2014 & Accompanied by dual pathology & $\mathrm{Y}$ & $\mathrm{N}$ & $\mathrm{N}$ & $(15)$ \\
\hline Giakoustidis & 2014 & Ciliated foregut cyst of the gallbladder & Y & $\mathrm{N}$ & $\mathrm{N}$ & $(16)$ \\
\hline Present case & 2014 & Common duct stones & $\mathrm{Y}$ & $\mathrm{N}$ & $\mathrm{N}$ & - \\
\hline
\end{tabular}

Y, yes; N, no; OC, open cholecystectomy.

A

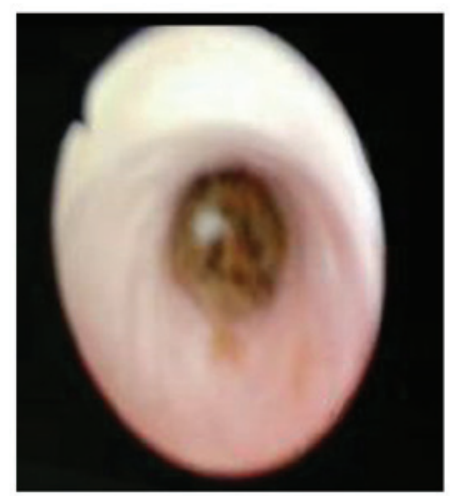

C

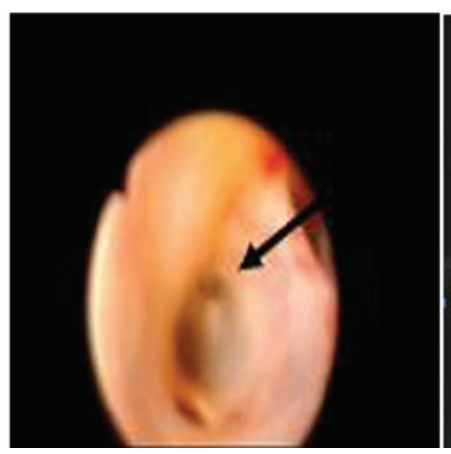

B
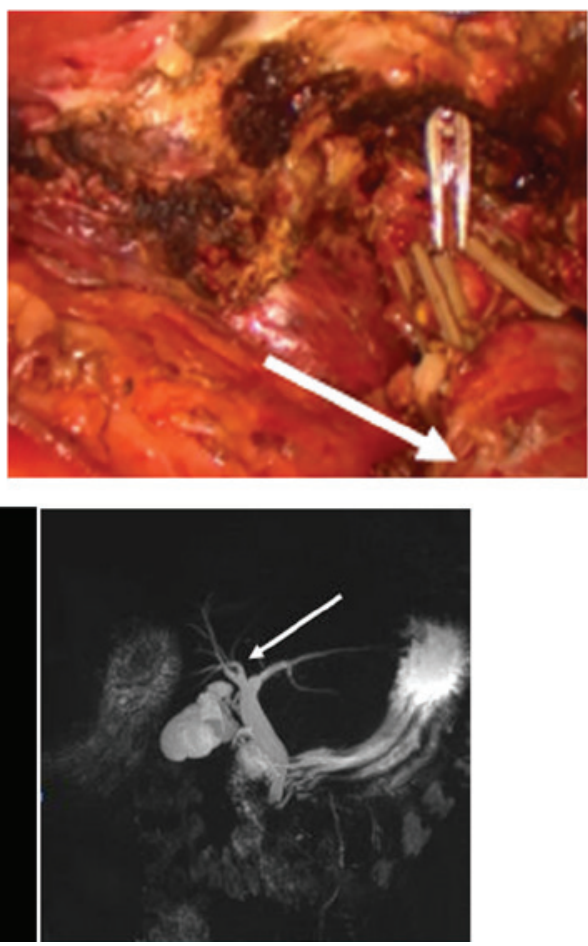

Figure 4. (A) Choledochoscopic exploration was performed in the proximal and distal common bile duct. (B) No residual gallbladder segments remained in the right side of the common bile duct (white arrow). (C) The structures of the proximal bile duct branches were consistent with those indicated by the magnetic resonance cholangiopancreatography, and the right hepatic bile duct extended to the secondary branches (black arrow) before the left hepatic bile duct (white arrow).

cholecystitis and gallstones have shown laparoscopic surgery results (Table I) (5-16).

Written informed consent was obtained from this patient prior to participation into the present study.

\section{Discussion}

Two cases of double gallbladders have been reported among 9,921 autopsy cases $(0.02 \%)$, and 3 cases have been reported 
out of a total of 9,970 cases $(0.03 \%)$ in a radiographic survey (1). Double gallbladders are classified according to Boyden's classification (1), which is the most widely used. The two primary duplication types consist of bi-lobed gallbladders and true duplications, the latter of which involves two separate cystic ducts. The true duplication type is subclassified into $\mathrm{H}$ - and $\mathrm{Y}$-shaped types. The $\mathrm{H}$-shaped subtype involves two separate cystic ducts that separately enter into the CBD, whereas the Y-shaped type describes two cystic ducts that are adjoined prior entering the $\mathrm{CBD}$. The reconstruction image obtained by MRCP indicated a complete (true) duplication of the gallbladder of the H-shaped type. The technology currently available facilitates the generation of clear preoperative anatomical images that provide anatomical details during surgery that could enable the prevention of intraoperative damage to the biliary duct, otherwise the double gallbladder may be missed (17).

Double gallbladder abnormalities are typically associated with gallstones and cholecystis, with sporadic reports of other anomalies. Kawanishi et al (18) reported a double gallbladder with an adenocarcinoma originating in the left hepatic duct. Nayak et al (17) reported a case concerning a double gallbladder completely enclosed in a cystogastric peritoneum fold. In addition, Ghosh (15) reported the case of a laparoscopic cholecystectomy of a double gallbladder with dual pathology, whilst Vijayaraghavan and Belagavi (11) reported a double gallbladder with different disease entities. Lefemine and Lazim (13) reported a double gallbladder neuroma. Papaziogas et al (9) reported a gallbladder with two chambers with separate cystic ducts, which communicated through an ostium, with both chambers containing multiple gallstones. However, a double gallbladder associated with CBD stones, particularly a case treated by laparoscopic surgery, has rarely been reported in previous studies (Table I) (5-16). The authors of the present study hypothesize that the H-shaped subtype (according to Boyden's classification) double gallbladders are more likely to form common bile duct stones. The possibility of gallstones migrating into the biliary tract would increase, and the hydrodynamics within the bile duct may have changed, leading to the formation of a vortex, and a minimal bile duct obstruction could result in a mild infection. Subsequently, the infection would then accelerate the formation of primary or secondary bile pigment stones as well as cholesterol-mixed stone pieces.

Double gallbladders associated with other anomalies present increased difficulties in cholecystectomies, and involve postoperative complications. A review of the studies published in English identified 13 laparoscopically-managed cases (13). The majority of cases did not require conversion to an open cholecystectomy (Table I). Goel et al (19) and Ozmen et al (20) have reported the use of laparoscopic treatment for a double gallbladder. For such rare variants, a complete analysis of the imaging data and patient intraoperative separation are necessary prior to the removal of any pipeline during LC surgery. In cases with the H-shaped subtype, the possibility of injury to the bile duct and hepatic artery is high (21). In the present case, the LC was successfully completed, despite the coexistence of acute and chronic cholecystitis. Thus, the present results indicate that the laparoscopic surgeon may not need to convert these cases to open procedures, and that the standard 4-port technique may suffice. Laparoscopic magnification provided a clear image of the details of Calot's triangle, and by performing a detailed blunt dissection of Calot's triangle with a layer-by-layer thinning procedure, the pipeline structure was able to be clearly separated (Fig. 3). Therefore, as in the present study, a retrograde resection should be applied and the gallbladder should be opened, when necessary, to confirm the location of the cystic duct from the cavity.

Choledochoscopy in LC surgery for a double gallbladder associated with CBD stones has unique advantages. In the current study, the second cystic duct (the upper branch) was utilized during surgery. The choledochoscope is inserted into the CBD at an almost right angle through the cystic duct, particularly in the upper part of the CBD. It is easier to directly enter and observe the intrahepatic bile duct branches and proximal residual stones than the lower cystic duct (Fig. 3), followed by removal of the remote stones (Fig. 4). The first cystic duct (the lower branch) is a reserve pathway. Choledochoscopy confirmed that the cavity structure in the proximal biliary was in complete accordance with that of the preoperative MRCP image (Fig. 4). In the present study, it was evident that there was no residual cystic structure on the right side of the CBD following the removal of the double gallbladder (Fig. 4). Thus, choledochoscopy is able to serve the same role as the operative cholangiography.

In conclusion, a double gallbladder associated with common duct stones is highly rare. It is safe and feasible to perform a meticulous laparoscopic dissection and removal of a double gallbladder, in addition to an exploration of the common duct for the removal of choledochoscopic stones following a micro-incision at the anterior wall of the cystic duct, with a primary suture of the cystic duct.

\section{References}

1. Boyden EA: The accessory gallbladder-an embryological and comparative study of aberrant biliary vesicles occurring inman and domestic mammals. Am J Anast 38: 177-231, 1926.

2. Cueto García J, Weber A, Serrano Berry F and Tanur Tatz B: Double gallbladder treated successfully by laparoscopy. J Laparoendosc Surg 3: 153-155, 1993.

3. Heinerman M, Lexer G, Sungler P, Mayer F and Boeckl O: Endoscopic retrograde cholangiographic demonstration of a double gallbladder following laparoscopic cholecystectomy. Surg Endosc 9: 61-62, 1995.

4. Silvis R,van Wieringen AJ and van der Werken $\mathrm{CH}$ : Reoperation for a symptomatic double gallbladder. Surg Endosc 10: 336-337, 1996.

5. Gorecki PJ, Andrei VE, Musacchio T and Schein M: Double gallbladder originating from left hepatic duct: a case report and review of literature. JSLS 2: 337-339, 1998.

6. Weibel D, Kaufmann M and Riedtmann-Klee HJ: Accessory gallbladder originating from the right hepatic duct. Surg Endosc 15: 519, 2001.

7. Schroeder C and Draper KR: Laparoscopic cholecystectomy for triple gallbladder. Surg Endosc 17: 1322, 2003.

8. Ohtani Y, Tobita K, Dowaki S, Sugio Y, Kashiwagi H, Tucker A and Makuuchi H: Duplicate gallbladder diagnosed with endoscopic retrograde cholangiopancreatography and treated with laparoscopic cholecystectomy. Dig Endosc 15: 69-71, 2003.

9. Papaziogas B, Lazaridis C, Paraskevas G, Koutelidakis J, Katsinelos P, Oikonomou B, Chatzimavroudis G, Grigoriou M and Atmatzidis K: A variant of the double gallbladder. A possible cause of cholelithiasis? Folia Morphol (Warsz) 64: 229-232, 2005.

10. Sasaki A, Yoshida T, Kakisako K, Ohta M, Shimoda K and Kitano S: Laparoscopic cholecystectomy for a double gallbladder of the duodenal type. Surg Laparosc Endosc Percutan Tech 15: $355-358,2005$. 
11. Vijayaraghavan R and Belagavi CS: Double gallbladder with different disease entities: A case report. J Minim Access Surg 2: 23-26, 2006.

12. Singh B, Ramsaroop L, Allopi L, Moodley J and Satyapal KS Duplicate gallbladder: An unusual case report. Surg Radiol Anat 28: 654-657, 2006.

13. Lefemine V and Lazim TR: Neuroma of a double gallbladder: A case report. Cases J 2: 11, 2009.

14. Walbolt TD and Lalezarzadeh F: Laparoscopic management of a duplicated gallbladder: A case study and anatomic history. Surg Laparosc Endosc Percutan Tech 21: e156-e158, 2011.

15. Ghosh SK: Laparoscopic cholecystectomy in double gallbladder with dual pathology. J Minim Access Surg 10: 93-96, 2014.

16. Giakoustidis A, Morrison D, Thillainayagam A, Stamp G, Mahadevan V and Mudan S: Ciliated foregut cyst of the gallbladder. A diagnostic challenge and management quandary. J Gastrointestin Liver Dis 23: 207-210, 2014.
17. Nayak SB, Shetty SD, Surendran S, Jetti R, Kumar N and Sirasanagandla SR: Double gallbladder completely enclosed in a cystogastric fold of peritoneum. Anat Cell Biol 47: 132-134, 2014.

18. Kawanishi M, Kuwada Y, Mitsuoka Y, Sasao S, Mouri T, Takesaki E, Takahashi T, Toyota K and Nakatani T: A case of double gallbladder with adenocarcinoma arising from the left hepatic duct: A case report and review of the literature. Gastroenterol Res Pract 2010: pii: 721946, 2010.

19. Goel A, Srivastava KN and Rana AK: Double gallbladder-a laparoscopic management. Surg Laparosc Endosc Percutan Tech 13: 348-349, 2003.

20. Ozmen V, Gorgun E, Unal ES, Polat C and Ozmen T: Laparoscopic treatment of a bilobed gallbladder: A case report and review of the literature. Surg Laparosc Endosc Percutan Tech 13: 345-347, 2003.

21. Hishinuma M, Isogai Y, Matsuura Y, Kodaira M, Oi S, Ichikawa N, Kosukegawa M and Kuriki K: Double gallbladder. J Gastroenterol Hepatol 19: 233-235, 2004. 